\title{
Improved Gasification of Rice Husks for Optimized Biochar Production in a Top Lit Updraft Gasifier
}

\author{
Hussein Kisiki Nsamba1,2,3*, Sarah E. Hale ${ }^{4}$, Gerard Cornelissen ${ }^{4}$, \\ Robert Thomas Bachmann ${ }^{1}$ \\ ${ }^{1}$ Malaysian Institute of Chemical and Bioengineering Technology (MICET), Universiti Kuala Lumpur, \\ Kuala Lumpur, Malaysia \\ ${ }^{2}$ Section of Industrial Chemistry, Department of Chemistry, Makerere University, Kampala, Uganda \\ ${ }^{3}$ Invention Plus Limited, Kampala, Uganda \\ ${ }^{4}$ Norwegian Geotechnical Institute (NGI), Oslo, Norway \\ Email: ${ }^{\text {hnnsamba@cns.mak.ac.ug }}$
}

Received 12 September 2014; revised 21 October 2014; accepted 22 November 2014

Copyright (C) 2014 by authors and Scientific Research Publishing Inc.

This work is licensed under the Creative Commons Attribution International License (CC BY).

http://creativecommons.org/licenses/by/4.0/

(c) (i) Open Access

\section{Abstract}

Biochar is a solid material obtained from the carbonization of biomass. If properly produced, it is useful for soil application to enrich plant values. Rice husk (RH) waste, an abundant agricultural by-product, was gasified in a top-lit updraft Belonio rice husk gasifier with a biochar yield of $29.0 \% \pm$ 1.9\%. The equivalence ratio (ER) for optimum biochar production was identified and its effect on biochar properties such as $\mathrm{pH}$, volatile matter (VM), fixed carbon (FC) and ash content (AC), electricity consumption, biochar yield, specific gasification rate (SGR) as well as reactor temperature investigated and statistically analyzed. As ER increased from $0.292 \pm 0.005$ to $0.442 \pm 0.016$, the SGR decreased from $85.4 \pm 4.5 \mathrm{~kg} /\left(\mathrm{m}^{2} \mathrm{hr}\right)$ to $51.6 \pm 2.4 \mathrm{~kg} /\left(\mathrm{m}^{2} \mathrm{hr}\right)$ whereas reactor temperature increased linearly with ER. The original VM content of RH was found to be $76.1 \% \pm 1.2 \%$ and decreased with increasing ER from $14.1 \% \pm 0.2 \%$ to $10.6 \% \pm 0.3 \%$. The original FC and AC of $5.49 \% \pm$ $0.22 \%$ and $9.10 \% \pm 1.23 \%$ increased with ER from $50.5 \% \pm 0.7 \%$ to $51.3 \% \pm 0.4 \%$ and $33.7 \% \pm 0.4 \%$ to $36.7 \% \pm 0.1 \%$ respectively. The biochar $\mathrm{pH}$ at low, medium and high ER was $9.36 \pm 0.11,9.64 \pm$ 0.03 and $9.42 \pm 0.01$, respectively. Results revealed a significant change in biochar yield and proximate values as ER changes from low to high.

\section{Keywords}

Equivalence Ratio, Biochar, Carbonization, Yield, Specific Gasification Rate

${ }^{*}$ Corresponding author.

How to cite this paper: Nsamba, H.K., Hale, S.E., Cornelissen, G. and Bachmann, R.T. (2014) Improved Gasification of Rice Husks forOptimized Biochar Production in a Top Lit Updraft Gasifier. Journal of Sustainable Bioenergy Systems, 4, $225-242$. 


\section{Introduction}

There is need to maintain soil fertility to sustain agricultural production. The dependence on artificial fertilizers is expensive and not sustainable. When biomass is left to decompose or openly burnt, carbon emissions escape to the atmosphere contributing to global warming while converting biomass to biochar reduces those emissions. Application of biochar to soils is currently gaining considerable interest globally due to its potential to improve soil nutrient retention capacity, water holding capacity and also to sustainably store carbon, thereby reducing greenhouse gas (GHG) emissions [1]-[3]. Biochar is the carbon-rich product remaining after biomass has been heated at low temperatures $\left(350^{\circ} \mathrm{C}-600^{\circ} \mathrm{C}\right)$ in an environment with little or no oxygen [4]. Exploring sustainable processes for its production will optimize biochar yield and enable small-scale farmers to apply biochar based on their land size and agricultural waste. Farmers will be motivated to apply biochar to their farms if these benefits can be demonstrated explicitly through various methods which include mixing with fertilizer and seed, applying through no till systems, uniform soil mixing, deep banding with plow, top-dressed, hoeing into the ground, applying compost and char on raised beds and spreading around farms to capture run off, although the type of application of biochar in soil depends on the farming system, available machinery and labour [3]. Malaysia, a southeast Asian country situated near the equator, has a tropical climate experiencing hot and wet weather throughout the year. This has provided very high prospects for agriculture and consequently an abundance of biomass species. Biomass is considered to be one of the main renewable energy resources of the future due to its large potential for economic viability and various social and environmental benefits [5]. All nations with significant biomass potentials are at the forefront of enjoying these benefits. Malaysia is a leader as one of the foremost agricultural countries in the world [6]. Major agricultural produces in Malaysia include palm oil, rubber, rice, coconut, cocoa, pepper, pineapple, tobacco, coffee, tea and sugarcane. These feedstocks and the tropical climate provide a great prospect for biomass investment with agriculture contributing about $10.6 \%$ to Malaysia's gross domestic product in 2010 [7]. Among the crops that Malaysia is endowed with is rice with the northern part of Malaysia being the rice bowl of the country which includes states of Perlis, Kedah, Penang and north of Perak. Paddy straws and rice husks (RH) are thus the main residues from paddy cultivation that are generated during the harvesting and milling processes. The paddy straw is left in the paddy field and RH is generated in the rice mill. Unless these wastes are put to optimal use, they will continue to pose challenges of waste management. The amount of RH and paddy straw generated in future is dependent on the planted area, the paddy yield and government policy [7]. The government provides a framework for clean and efficient waste management practices which align with both local and international standards such as the clean development mechanism (CDM). The CDM under the Kyoto Protocol is a scheme to promote sustainable development through emission reductions. It introduces carbon credits through which developing countries can gain profit by trading certified emission reductions (CER), while developed countries can achieve their emission reduction targets by purchasing the tradable carbon credits [8]. The RH biomass industry is eligible to earn CER if biochar from RH is produced under controlled conditions. For biochar to be produced in a top lit updraft gasifier such as the original Belonio rice husk gasifier (OBRHG), air is generally employed as the gasifying agent and the biomass is partially oxidized to provide the heat necessary to make the process self-sufficient [9]. The biochar yield thus depends on the operating conditions such as the amount of air used during gasification and the particle size of RH. Original rice husk (ORH) as RH in its original form and fine rice husk (FRH) as rice husk that is partially broken were tested in this gasifier because they both exert a different pressure drop and the amount of air used for gasification will be different for both. It is the purpose of this work to run the OBRHG on RH at various ER and determine temperature profile inside the reactor, gas velocity and temperature, yield and the characteristics of the produced rice husk biochar (RHB).

\section{Material and Methods}

\subsection{RH Collection}

RH samples of approximately $15 \mathrm{~kg}$ per polyethylene bag were collected from KilangBerasHonSdnBhd (Lot 5500, Jalan PDR 41, Kawasan Perinustrian Bukit Melaka 75250 Melaka, Malaysia). The RH bags were stored in an outdoor shelter comprising of a fence and zinc roofing to prevent rain from wetting the RH.

\subsection{RH Sample Preparation and Proximate Analysis}

Air dried biomass samples were ground slowly using pestle and mortar to obtain a uniform material [10]. The 
RH was characterized for proximate analysis according to ASTM standards [11] and [12] using a muffle furnace (Carbolite ELF 11/14B) and analytical balance (Mettler Toledo; B204-S; 0 - $220 \mathrm{~g}$ ). In brief, moisture content (MC) of oven-dried ground specimen was calculated as follows:

$$
\mathrm{MC}, \%=\frac{A-B}{A} \times 100
$$

where $A=$ weight of air dry sample [g], $B=$ weight of sample after drying at $105^{\circ} \mathrm{C}[\mathrm{g}]$.

The moisture-free specimen was subsequently used for volatile matter (VM) and ash content (AC) determination. VM was determined by pre-heating the MC-free specimen in a muffle furnace for two minutes at $300^{\circ} \mathrm{C}$ then heating for three minutes at $500^{\circ} \mathrm{C}$ and for six minutes at $950^{\circ} \mathrm{C}$. VM content was calculated as a proportion of the oven-dry weight of the charcoal specimen:

$$
\mathrm{VM}, \%=\frac{B-C}{B} \times 100
$$

where $C=$ weight of sample after heating at $950^{\circ} \mathrm{C}[\mathrm{g}]$.

$\mathrm{AC}$ was determined by heating the $\mathrm{RH}$ specimen in an uncovered crucible at $750^{\circ} \mathrm{C}$ for six hours. The ash samples were allowed to cool down in a desiccator and then weighed. AC was calculated as a proportion of the oven-dry weight of the oven-dry weight of the residue to the oven-dry weight of specimen:

$$
\text { Ash, } A \%=\frac{D}{B} \times 100
$$

where $D=$ weight of residue [g].

Results are reported on a dry basis unless stated otherwise.

\subsection{Bulk Density}

Bulk density of RH was determined according to ASTM E-873-82 [11]. In brief, an empty cylindrical container ( $9 \mathrm{~cm}$ in circumference and $56.2 \mathrm{~cm}$ high, inside dimensions) was weighed using an analytical balance (Mettler Toledo; B204-S). The container was filled by pouring loose RH from the top edge of the container. The container and sample were then weighed, and the net mass of the material was divided by the volume of the RH in the container to obtain the bulk density $\rho_{b}\left(\mathrm{~kg} / \mathrm{m}^{3}\right)$ as follows:

$$
\rho_{b}=\frac{W_{1}-W_{0}}{V}
$$

where $W_{1}=$ weight of the container with sample $[\mathrm{kg}], W_{0}=$ weight of the container $[\mathrm{kg}]$, and $V=$ volume of the container $\left[\mathrm{m}^{3}\right]$.

\subsection{Experimental Procedure for Biochar Production in OBRHG}

Biochar was produced in the OBRHG (Figure 1) by following the steps below:

1. Weigh $1.0 \mathrm{~kg}$ for ORH or $1.8 \mathrm{~kg}$ for FRH of dried RHs;

2. Transfer the preweighed RHs without loss into the reactor intervally;

3. Close char chamber and seal any gaps with tape to ensure no air leakage from the reactor. Run the fan at maximum power and measure the air velocity at the inlet with the anemometer (BENETECH, GM8908). At maximum fan speed the incoming air velocity must be $1.8 \mathrm{~m} / \mathrm{s}$ (equivalent to $6.44 \times 10^{-4} \mathrm{~m}^{3} / \mathrm{s}$ ) to confirm no air leakage occurred and ensure reproducible experimental conditions;

4. Monitor electricity consumption using a power cost monitor (EMC/LVD);

5. $10 \mathrm{~g}$ of small pieces of paper are put on top of the RH and ignited using a lighter;

6. After $1-2$ min the combustion process has initiated, burnerhead is placed on top of the OBRHG and the counting time starts for both the time required to complete the gasification for each cycle as well as the electricity consumed by the fan. The temperatures along the gasifier height are also monitored using a K-type thermocouple attached to a datalogger (Figure 1 and Section 2.6);

7. The end of the gasification process is confirmed by either a change of the syngas appearance from being very smokey to being smokeless (high ER) or the grate region becoming very hot confirming that the gasifica- 


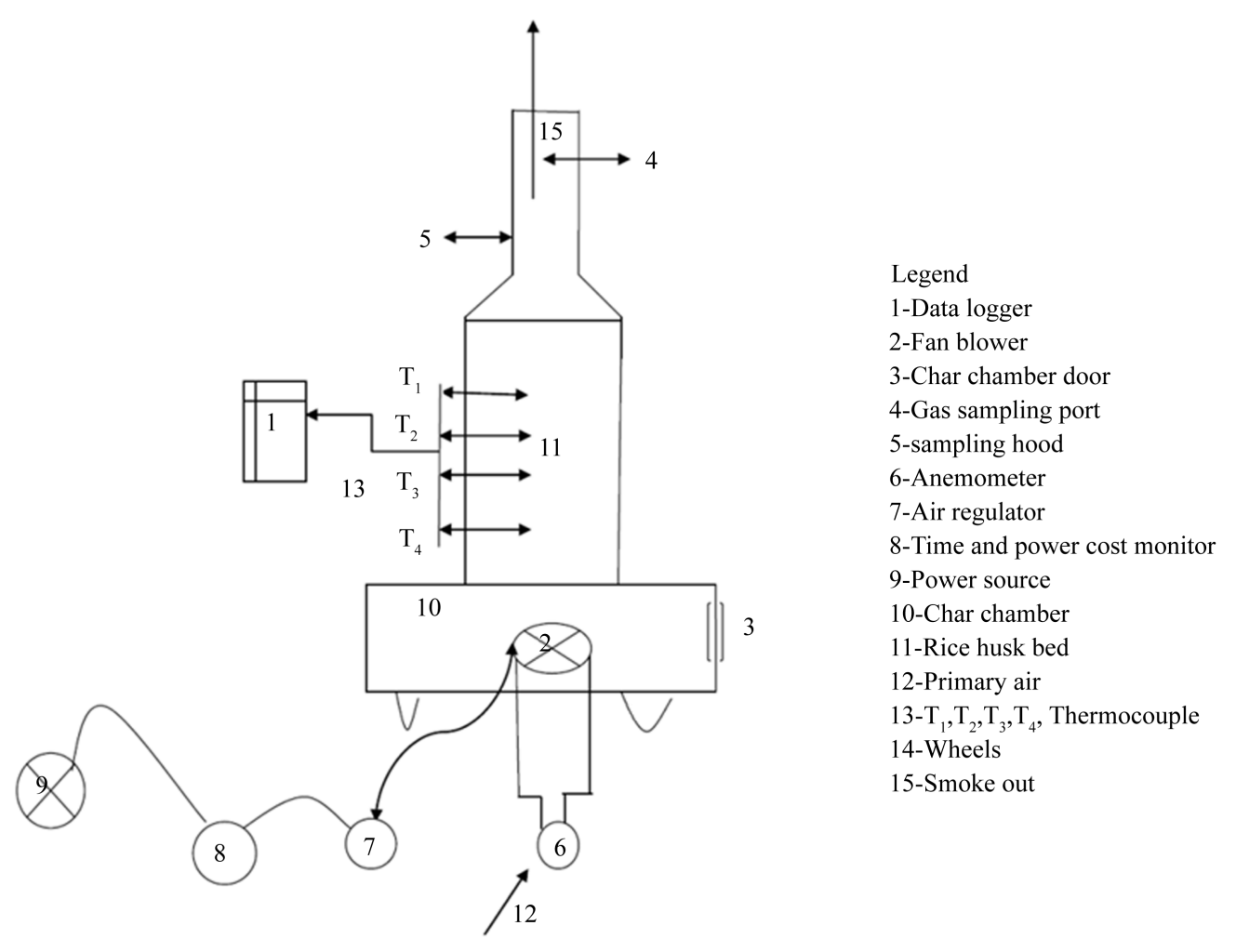

Figure 1. Schematic diagram of the experimental set up.

tion zone has reached the bottom of the gasifier (low ER). In either case, the fan is stopped, the power consumption and the time taken to complete the gasification process noted, burnerhead removed and the char chamber opened;

8. The hot char is carefully removed using a handheld mini spade, unburnt RH separated if any, then weighed and cooled in covered metal buckets containing ice packs to avoid char oxidation by the surrounding air;

9. Once the total number of cycles in a day is concluded, the reactor is left to cool until experiments resume the next day.

\subsection{Char Yield}

The char yield $(\% \mathrm{w} / \mathrm{w})$ was calculated using the following equation:

$$
\text { Biochar yield }=\frac{W_{c}}{W_{w}} \times 100
$$

where $W_{c}=$ dry weight of biochar obtained $[\mathrm{g}]$ and $W_{w}=$ oven-dry weight of $\mathrm{RH}[\mathrm{g}]$.

\subsection{Temperature and Velocity Monitoring}

The temperature along the reactor height was monitored at $1 \mathrm{~s}$ intervals using a data logger (TM-747DU, TENMARS). The data logger was fixed with four K-type thermocouples (TP20000008) supplied by UniDex (Malaysia) Sdn. Bhd placed equidistantly along the reactor height. Incoming air velocity and temperature was monitored with an anemometer (BENETECH, GM8908) throughout the experimental period. The volumetric flow rate was computed as a product of incoming air velocity and the cross sectional area for the anemometer air inlet.

\subsection{Calculation of ER}

ER is defined as the ratio of the actual fuel-to-oxidizer ratio to the stoichiometric fuel-to-oxidizer ratio [13] [14]. 


$$
\mathrm{ER}=\frac{Q \times T}{M \times\left(\frac{A}{F}\right)}
$$

where $Q=$ rate of air supply $\left[\mathrm{m}^{3} / \mathrm{s}\right], T=$ duration of the run [hr], $M=$ dry $\mathrm{RH}$ biomass input $[\mathrm{kg}], A / F=$ air-tofuel ratio at ER of $1\left[\mathrm{~m}^{3} / \mathrm{kg}\right]$.

\subsection{Determining the $\mathrm{pH}$}

A $0.5 \mathrm{~g}$ RHB sample was soaked with $20 \mathrm{ml}$ of distilled water [10] and boiled for around $10 \mathrm{~min}$ [15]. The solution was allowed to cool down to room temperature, filtered using Whatman 40 filter paper and the $\mathrm{pH}$ was observed using a pre-calibrated $\mathrm{pH}$ meter (Sension 3, Hach).

\subsection{Specific Gasification Rate (SGR)}

SGR is defined as the amount of biomass fuel used per unit time per unit reactor area [16] and was calculated as:

$$
\mathrm{SGR}=\frac{\dot{m}_{f}}{A}
$$

where $m_{f}=$ fuel mass flow rate $[\mathrm{kg} / \mathrm{hr}]$ and $A=$ reactor cross-sectional area $\left[\mathrm{m}^{2}\right]$.

\subsection{Empirical Formula of RH}

The empirical formula for RH was first computed based on literature (Table 1) in order to establish the stoichiometric equation for complete RH gasification used for estimating the ER.

The empirical formula of RH can be computed as follows:

Consider the equation of rice husk as $\mathrm{C}_{a} \mathrm{H}_{b} \mathrm{O}_{c} \mathrm{~N}_{d}$ where $a, b, c$ and $d$ are subscripts. Assume $a=1$ and by using the formula

$$
\begin{aligned}
& b=\frac{\text { mass fraction of Hydrogen } \times \text { Molecular weight of Carbon }}{\text { mass fraction of carbon } \times \text { Molecular weight of Hydrogen }} \\
& b=\frac{6.3 \times 12}{48.8 \times 1}=1.5 \\
& c=\frac{\text { mass fraction of Oxygen } \times \text { Molecular weight of Carbon }}{\text { mass fraction of carbon } \times \text { Molecular weight of Oxygen }} \\
& c=\frac{44.2 \times 12}{48.8 \times 16}=0.7 \\
& d=\frac{\text { mass fraction of Nitrogen } \times \text { Molecular weight of Carbon }}{\text { mass fraction of carbon } \times \text { Molecular weight of Nitrogen }} \\
& d=\frac{0.7 \times 12}{48.8 \times 14}=0.01
\end{aligned}
$$

Thus the general RH chemical formula used was $\mathrm{CH}_{1.5} \mathrm{O}_{0.7} \mathrm{~N}_{0.01}$.

\subsection{ER for RH Gasification with Air}

The net area of the circular cross section of the anemometer, $A_{\text {nett,air }}$ (Figure 2) that allows incoming air was computed as:

$$
A_{\text {nett,air }}=A_{\text {fan,total }}-A_{\text {fan,blade }}-A_{\text {fan,rotor }}
$$

where $A_{\text {fan,total }}=$ total cross-sectional area of fan $\left[\mathrm{cm}^{2}\right], A_{\text {fan,blade }}=$ cross-sectional area of fan blades $\left[\mathrm{cm}^{2}\right], A_{\text {fan,rotor }}$ $=$ cross-sectional area of fan rotor $\left[\mathrm{cm}^{2}\right]$. 
Table 1. Average elemental composition of RH based on literature values.

\begin{tabular}{ccccccccc}
\hline & $\mathbf{C}$ & $\mathbf{H}$ & $\mathbf{O}$ & $\mathbf{N}$ & Ash & Moisture & Reference \\
$\mathbf{1}$ & 48.5 & 6.16 & 44.6 & 0.55 & 19.5 & 10.3 & {$[17]$} \\
$\mathbf{2}$ & 48.7 & 5.91 & 44.6 & 0.65 & 20.5 & 10.0 & {$[15]$} \\
$\mathbf{3}$ & 48.9 & 6.2 & 44.1 & 0.8 & 17.9 & na & {$[18]$} \\
$\mathbf{4}$ & 47.2 & 6.37 & 45.6 & 0.80 & 8.93 & 9.37 & na & {$[19]$} \\
$\mathbf{5}$ & 50.8 & 6.66 & 41.8 & 0.78 & 23.5 & & \\
Mean [\%] & 48.8 & 6.3 & 44.2 & 0.7 & 18.1 & 9.9 & \\
SD [\%] & 1.3 & 0.3 & 1.4 & 0.1 & 5.5 & 0.5 & \\
\hline
\end{tabular}

na: not available.

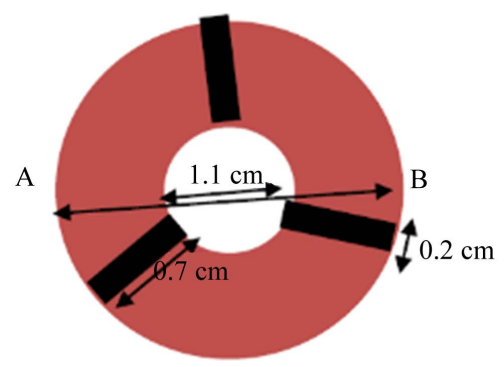

Figure 2. Schematic representation of air space in red color. Diameter $A B=2.5 \mathrm{~cm}$; diameter inner circle, $d=1.1 \mathrm{~cm}$; Length of rectangle, $L$ $=0.7 \mathrm{~cm}$; Width of Rectangle, $W=0.2 \mathrm{~cm}$.

$$
\begin{aligned}
& =\pi \frac{D_{A B}^{2}}{4}-3(L \times W)-\pi \frac{d^{2}}{4} \\
& =\pi \frac{2.5^{2}}{4}-3(0.7 \times 0.2)-\pi \frac{1.1^{2}}{4}=3.5384 \mathrm{~cm}^{2}
\end{aligned}
$$

\subsection{Calculating the ER}

From the stoichiometric equation for complete combustion of $\mathrm{RH}\left(\mathrm{CH}_{1.5} \mathrm{O}_{0.7} \mathrm{~N}_{0.01}\right)$, nitrogen content from the equation can be ignored for simplicity, thus

$$
\begin{aligned}
& \mathrm{CH}_{1.5} \mathrm{O}_{0.7}+1.025\left(\mathrm{O}_{2}+3.76 \mathrm{~N}_{2}\right) \rightarrow \mathrm{CO}_{2}+0.75 \mathrm{H}_{2} \mathrm{O}+1.025\left(3.76 \mathrm{~N}_{2}\right) \\
& \text { Grams of fuel }(\mathrm{RH})=(12 \times 1)+(1 \times 1.5)+(0.7 \times 16)=24.7 \mathrm{~g}_{\mathrm{rh}} \text { or } 24.7 \times 10^{-3} \mathrm{~kg}_{\mathrm{rh}} \\
& \text { Grams of air }=1.025((2 \times 16)+(3.76 \times 2 \times 14))=140.712 \mathrm{~g}_{\text {air }} \text { or } 140.712 \times 10^{-3} \mathrm{~kg}_{\text {air }} \\
& \text { Density of air, } \rho \text { air }=\frac{\text { Mass of incoming air }(M) \times \operatorname{Pressure}(P)}{\text { Gas constant }(R) \times \text { Temperature }(T)}=\frac{M P}{R T} \\
& \text { aair }_{31.52^{\circ} \mathrm{C}}=\frac{28.97}{8.314 \mathrm{~m}^{3} \frac{\mathrm{kg}}{\mathrm{kmol}} \times 304.67 \mathrm{k}}=1.1588 \frac{\mathrm{kg}}{\mathrm{m}^{3}} \\
& \text { Volume of air }=\frac{\text { mass of air }}{\text { density of air }}=\frac{140.712 \times 10^{-3} \mathrm{~kg}_{\text {air }}}{\frac{1.1588 \mathrm{~kg}^{2}}{\mathrm{~m}^{3}}}=0.1214 \mathrm{~m}_{\text {air }}^{3}
\end{aligned}
$$




$$
\begin{gathered}
\text { Air to fuel ratio }\left(\frac{A}{F}\right) \text { at } E R_{=1}=\frac{\text { volume } \operatorname{Air}\left(\mathrm{m}^{3}\right)}{\text { Mass of Rice husk }(\mathrm{kg})}=\frac{0.1214 \mathrm{~m}_{\text {air }}^{3}}{24.7 \times 10^{-3} \mathrm{~kg}_{\mathrm{rh}}}=4.9161 \frac{\mathrm{m}^{3}}{\mathrm{~kg}} \\
\left(\frac{A}{F}\right) \text { at } Q_{=1}=4.9161 \mathrm{~m}^{3} / \mathrm{kg}_{\mathrm{rh}}
\end{gathered}
$$

\section{Results and Discussion}

\subsection{Characterization of RH and RHB}

Table 2 summarizes the proximate results of RH revealing a higher VM content $(76.1 \% \pm 1.2 \%)$ compared to RHB $(11.4 \% \pm 1.3 \%)$. When the RH is gasified from low to high ER $(0.292 \pm 0.005$ to $0.442 \pm 0.016)$, the VM component decreased from $14.1 \% \pm 0.2 \%$ to $10.6 \% \pm 0.3 \%$, AC increased from $33.7 \% \pm 0.4 \%$ to $36.7 \% \pm 0.1 \%$ while FC increased from $50.5 \pm 0.7$ to $51.3 \% \pm 0.4 \%$ (Figure 3). The higher the ER, the lower the VM, because more organic (volatile) matter is oxidized resulting in higher temperatures. The increase in AC as ER increased arises due to the oxidation of organic matter leaving more inorganic compounds as ash. This also explains the increase in FC as more VM are expelled. A similar trend in proximate analysis was observed by Angin (2013) during the pyrolysis of safflower seed press cake. When the temperature increased from $400^{\circ} \mathrm{C}$ to $600^{\circ} \mathrm{C}$ at a heating rate of $10^{\circ} \mathrm{C} / \mathrm{min}$, the $\mathrm{VM}$ content of the biochars decreased from $25.2 \%$ to $11.6 \%$, the $\mathrm{AC}$ of the biochars increased from $7.50 \%$ to $9.20 \%$ while the FC content of the biochars increased to as high as $79.2 \%$ $80.7 \%$.

\begin{tabular}{|c|c|c|c|}
\hline & As Received & Dry Basis & Dry Ash Free (d.a.f.) \\
\hline Moisture content, $\%$ & $9.35 \pm 0.22$ & & \\
\hline Volatile matter, $\%$ & $76.1 \pm 1.2$ & 83.9 & 93.3 \\
\hline Fixed carbon, $\%$ & $5.49 \pm 0.22$ & 6.06 & 6.73 \\
\hline Ash content, $\%$ & $9.10 \pm 1.23$ & 10.0 & \\
\hline Bulk density, $\mathrm{kg} / \mathrm{m}^{3}$ & $147 \pm 3$ & & \\
\hline
\end{tabular}

\section{Table 2. Proximate analysis of raw $\mathrm{RH}(\mathrm{n}=3)$.}

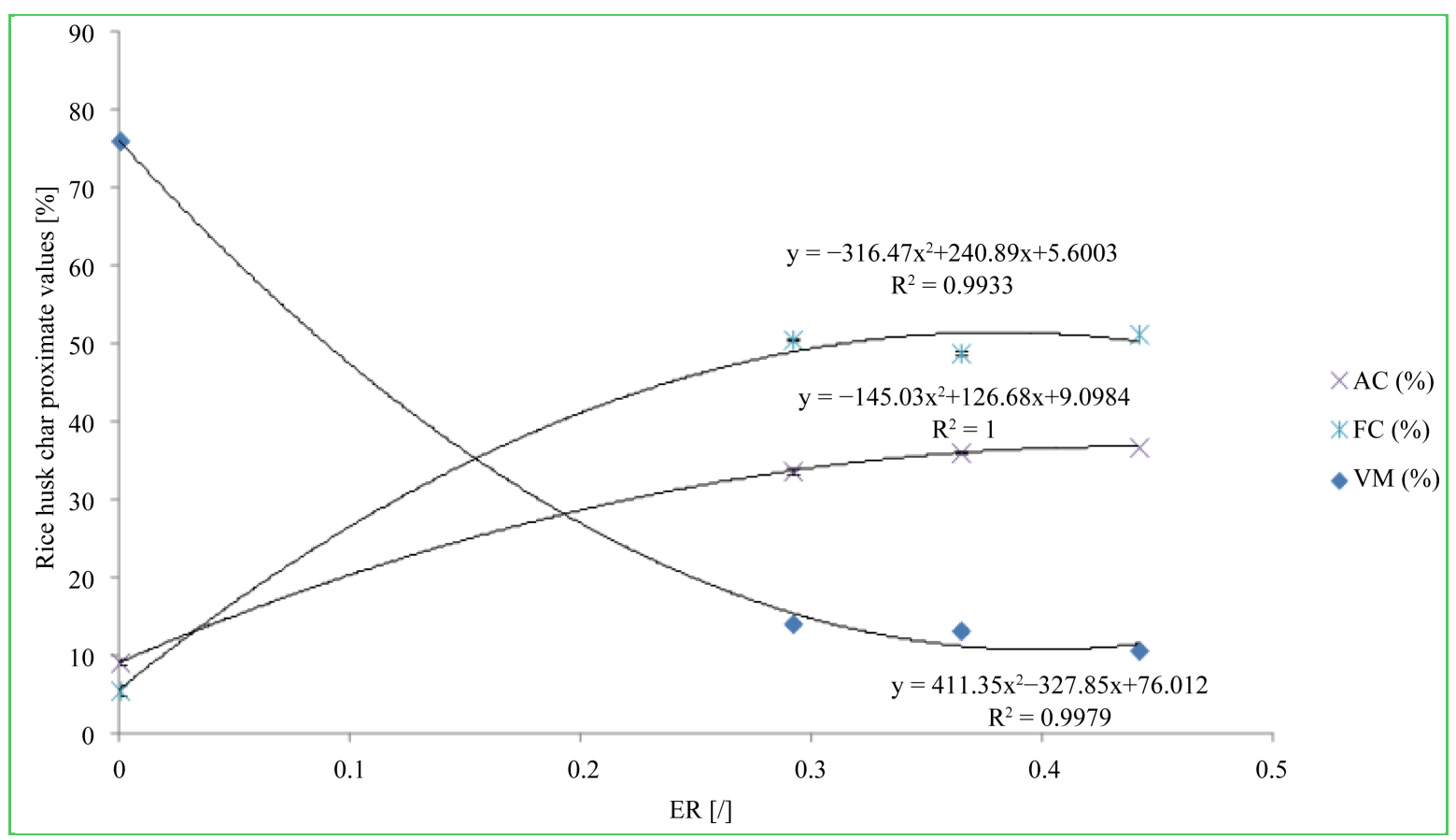

Figure 3. Variation of ER with proximate values of RHB. 
The results of the elemental analysis of biochars at various ER are shown in Table 3. The elemental analysis reveals that the carbon fraction present in biochar decreased from $45.8 \% \pm 4.46 \%$ to $21.1 \% \pm 5.1 \%$, while elemental hydrogen increased from $0.87 \% \pm 0.23 \%$ to $3.09 \% \pm 0.72 \%$, elemental nitrogen decreased by nearly a half from $1.08 \% \pm 0.42 \%$ to $0.52 \% \pm 0.28 \%$ and elemental sulphur decreased from $0.07 \% \pm 0.02 \%$ to $0.03 \% \pm$ $0.01 \%$ as ER increased. Generally, the loss of hydrogen during rice husk gasification is caused by dehydration and dehydrogenation reactions, and the cleavage and cracking of weak hydrogen bonds within the char structure. Losses in hydrogen correspond to the scission of weaker bonds within char structure favored by higher temperatures [21]. The increase in H content in RHB as ER increased seemed to differ from the expected trend which implied that ER was not the primary factor controlling the concentration of $\mathrm{H}$. The decrease in carbon is due to increase in thermal oxidation leading to loss of carbon in form of $\mathrm{CO}_{2}$ and $\mathrm{CO}$. At higher ER, there is more cracking and devolatilization creating bigger pore holes inside the biochar. This is in agreement with Petersen and Jackson [22] whose biochar BET analysis revealed that samples with low surface area seem to have large, flat surfaces that have partial cracking, compared to the higher surface area samples for which the cracking is further developed and there are more individually shaped spherical particles. From literature [23]-[25], biochar surface area increased directly with treatment temperature due to increased volatilization of organic material, leaving a porous structure consisting of the mineral and carbon-based vascular tissue. The decrease in elemental nitrogen and sulphur may be due to their oxidation to nitrous gases and sulphurdioxide which occur at higher temperatures available as ER increases. Their escape in the gaseous phase leaves little of their elemental composition. The lower the $\mathrm{O} / \mathrm{C}$ and $\mathrm{H} / \mathrm{C}$ ratios, the higher is the loss of oxygen and hydrogen during the combustion process [26] producing a product richer in higher elemental carbon. This is agreement with results in Table 3 which reveals less oxygen content of $15.6 \%$ in biochar at low ER compared to $29.0 \%$ and $38.6 \%$ at medium and high $\mathrm{ER}$, respectively. As the ER increased from $\mathrm{ER}=0, \mathrm{H} / \mathrm{C}$ and $\mathrm{O} / \mathrm{C}$ molar ratios first declined from 1.5 to 0.228 and 0.7 to 0.255 , then gradually increased to 1.76 and 1.37 , respectively, implying that the biochars became increasingly less aromatic and carbonaceous. This observation is in disagreement with $\mathrm{Fu}$ et al. [21] whose finding revealed a continuous decrease in $\mathrm{H} / \mathrm{C}$ and $\mathrm{O} / \mathrm{C}$ molar ratios as the temperatures increased. This variability of results may be explained by the intrinsic properties of the biomass feedstock (i.e. chemical composition), and partly also by differences in process conditions during the thermal decomposition [27]. In this case, autothermal and allothermal gasifiers have different holding times at peak temperature which can play a critical role in the carbonization efficiency, especially in the cases where the heat transfer limitations at all scales (inter- and intra-particle) are not negligible. It should be noted that the experiments performed by Fu et al. [21] were conducted in an externally heated (allothermal) fixed bed system whose temperature distribution and temperature peak residence time differs from that of an autothermal system used in this experiment. The International Biochar Initiative (IBI) [28] recommends only a maximum value of 0.7 for the molar $\mathrm{H} / \mathrm{C}$ ratio [26] which distinguishes biochars from biomass that has not or only partially been thermo-chemically altered. Lower ER should therefore be considered if carbon enriched biochars must be produced in the OBRHG.

ANOVA single factor was used to test the levels of significance with an alpha level of 0.05 . A statistically significant difference $(p=0.0032)$ between VM was found as ER changed from low to high. For AC statistical analysis, the $\mathrm{P}$ value $(0.03)$ was less than the significance level $(0.05)$ hence there is significant difference between $\mathrm{AC}$ as ER changed from low to high. It is preferable to operate the reactor at a lower ER in order to obtain a RHB rich in FC. Table 4 reveals the results with levels of significance at different ERs.

\subsection{RHB Production from FRH at High ER}

Once the RH bed was ignited at the top, the pyrolysis front propagated continuously into the bed by transfer of

Table 3. Ultimate analysis of RHB produced at three different ERs.

\begin{tabular}{cccc}
\hline & Low ER $(\mathbf{0 . 1 1} \pm \mathbf{0 . 0 2})$ & Medium ER (0.292 $\pm \mathbf{0 . 0 0 5})$ & High ER $(\mathbf{0 . 4 7} \pm \mathbf{0 . 0 3})$ \\
\hline $\mathbf{C}$ & $45.8 \pm 4.5$ & $30.0 \pm 1.7$ & $21.1 \pm 5.1$ \\
$\mathbf{H}$ & $0.870 \pm 0.233$ & $4.50 \pm 0.728$ & $3.09 \pm 0.72$ \\
$\mathbf{N}$ & $1.08 \pm 0.42$ & $0.550 \pm 0.317$ & $0.516 \pm 0.277$ \\
$\mathbf{S}$ & $0.0685 \pm 0.0203$ & $0.0421 \pm 0.0205$ & $0.0264 \pm 0.0104$ \\
$\mathbf{O}$ & 15.6 & 29.0 & 38.6 \\
\hline
\end{tabular}


Table 4. Variation in significance of major parameters as ER varies.

\begin{tabular}{cccc}
\hline & H & M & L \\
\hline VM & $25.88 \mathrm{ab}$ & $42.51 \mathrm{ab}$ & $49.37 \mathrm{ab}$ \\
& $23.06 \mathrm{ab}$ & $42.03 \mathrm{ab}$ & $51.20 \mathrm{ab}$ \\
& $18.47 \mathrm{ab}$ & $42.45 \mathrm{ab}$ & $59.83 \mathrm{ab}$ \\
& $51.05 \mathrm{a}$ & $49.06 \mathrm{a}$ & $51.10 \mathrm{a}$ \\
& $51.72 \mathrm{a}$ & $48.58 \mathrm{a}$ & $49.73 \mathrm{a}$ \\
& $51.05 \mathrm{a}$ & $48.84 \mathrm{a}$ & $27.02 \mathrm{ab}$ \\
& $20.30 \mathrm{ab}$ & $22.26 \mathrm{ab}$ & $26.31 \mathrm{ab}$ \\
& $21.57 \mathrm{ab}$ & $21.67 \mathrm{ab}$ & $29.11 \mathrm{ab}$ \\
& $18.16 \mathrm{ab}$ & $22.34 \mathrm{ab}$ & $29.50 \mathrm{ab}$ \\
& $15.96 \mathrm{ab}$ & $25.09 \mathrm{ab}$ & $30.70 \mathrm{ab}$ \\
& $16.66 \mathrm{ab}$ & $26.56 \mathrm{ab}$ & $31.30 \mathrm{ab}$ \\
& $17.2 \mathrm{ab}$ & $25.91 \mathrm{ab}$ & $9.43 \mathrm{ab}$ \\
\hline
\end{tabular}

H: high ER; M: medium ER; L: lower ER; a: not statistically significant; ab: statistically significant according to ANOVA single factor at alpha level of 0.05 .

the heat released from the gaseous reactions and char oxidation. The average SGR and ER are based on the mass loss during the whole period [29]. The experimental results are shown in Table 5. At higher ER, the average ER with fine RH was $0.442 \pm 0.016$ with an average power consumption and char yield of $27.6 \pm 2.4 \mathrm{~W} \cdot \mathrm{h}$ and $20.0 \% \pm$ $1.7 \%$, respectively. The average gasification time for the runs was $70.3 \pm 3.8 \mathrm{~min}$, which corresponds to an average SGR of $85.4 \pm 4.5 \mathrm{~kg} /\left(\mathrm{m}^{2} \cdot \mathrm{hr}\right)$. Run 1 and 3 were started from a cold start process while Run 2 was a direct continuation of Run 1 because they were performed on the same day under similar conditions. This explains why the gasification time of Run 2 was 6 min less than that of Run 1. Being a continuation of Run 1, the reactor was still hot and there was less energy and time required to heat up the reactor. Similarly, this accounted for the difference in electricity consumption of Run 2 from Runs 3 and 1. For future experiments, it is thus important to operate the reactor under the same operating mode for improved precision. At this maximum fan setting, there was low yield of RHB $(20.0 \% \pm 1.7 \%)$, due to a greater amount of air supplied that reacts with the RH to convert most of it into gaseous products. When the ER is higher, more heat is produced due to the oxidation reactions which are exothermic and increase the conversion of reactant RH to product gases. There is increased volatilization of components within the feedstock as the temperature of the process increases [22]. For all runs, the velocity of incoming air increased with gasification time (Figure 4) arguably due to a loss in pressure drop caused by conversion of RH to gas and decrease in bulk density.

\section{Gasification Temperature Profile for High ER}

In autothermal gasifiers, the temperature is controlled by the ER [30]. The temperature was monitored at different ERs via four thermocouples (T1 - T4) as illustrated in Figure 5. The thermocouples provide a means to trace the pyrolysis front as it moves downwards. Temperature readings were dynamic inside the reactor and thus not possible to reveal a single constant temperature for biochar production as typically reported for allothermal gasification experiments. It can however be given as a range depending on the peak temperature. The change in gasification temperature during gasification of FRH as a function of ER is shown in Figures 5-7. Once the FRH was ignited at the top, the combustion zone moved downwards by transfer of the heat released from the gaseous reactions and char oxidation. For all three runs, a general increase in temperature along the reactor height in the order T1 $>\mathrm{T} 2>\mathrm{T} 3>\mathrm{T} 4$ was observed. When the ignition front passed each thermocouple, a sharp rise of temperature was observed. The decrease in temperature after gasification zone passed each thermocouple occurred as the reduction reactions play a more dominant role as well as shrinkage in biomass. For all runs, T1 exponentially increases from ambient temperature to $450^{\circ} \mathrm{C}, 710^{\circ} \mathrm{C}$ and $700^{\circ} \mathrm{C}$, respectively, and subsequently slowly 
Table 5. Summary of results for high ER.

\begin{tabular}{|c|c|c|c|c|c|}
\hline Parameter & Run 1 & Run 2 & Run 3 & Average & SD \\
\hline Electricity consumption $[\mathrm{W} \cdot \mathrm{h}]$ & 27.9 & 25 & 29.8 & 27.6 & 2.4 \\
\hline Unburnt FRH [g] & 53.3 & 38.3 & 14.3 & 35.3 & 16.1 \\
\hline Yield [\%] & 18.2 & 21.6 & 20.3 & 20.0 & 1.7 \\
\hline $\mathrm{ER}[/]$ & 0.4539 & 0.4238 & 0.4470 & 0.442 & 0.016 \\
\hline Gasification time [min] & 72 & 66 & 73 & 70.3 & 3.8 \\
\hline Ambient temperature $\left[{ }^{\circ} \mathrm{C}\right]$ & 24.7 & 28.3 & 26.9 & 26.6 & 1.8 \\
\hline $\operatorname{SGR}\left[\mathrm{kg} / \mathrm{m}^{2} \cdot \mathrm{hr}\right]$ & 82.4 & 90.6 & 83.1 & 85.4 & 4.5 \\
\hline
\end{tabular}

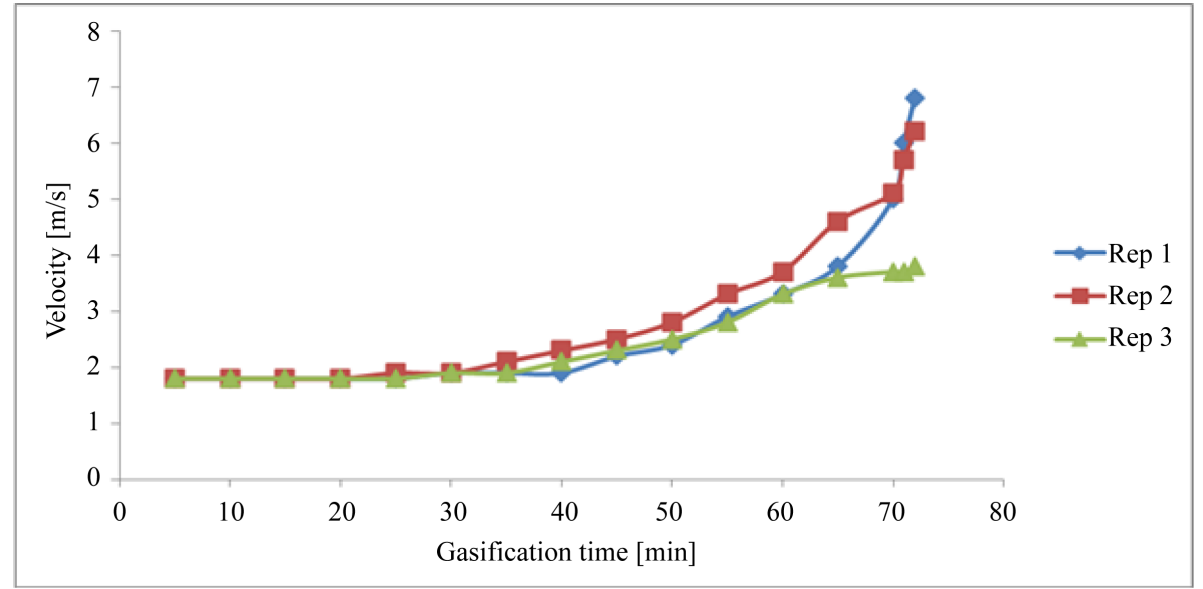

Figure 4. Change of inlet air velocity with gasification time in OBRHG (high ER).

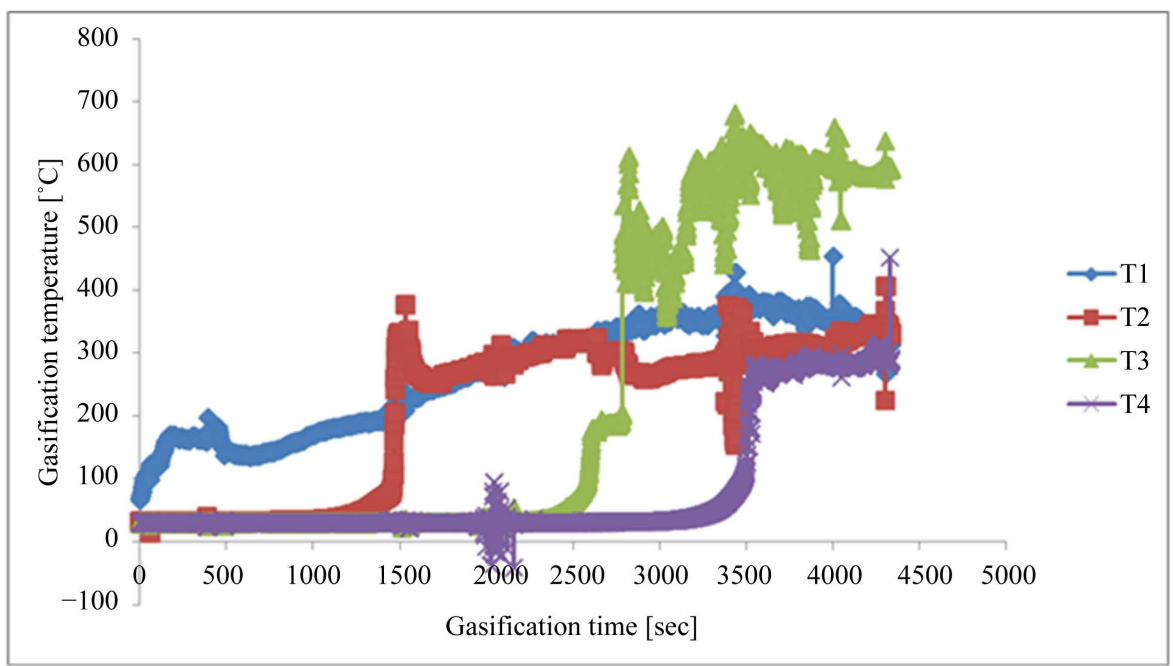

Figure 5. Variation of gasification temperature with gasification time Run 1.

declined over time. Such a small relative change in the temperature gradient is due to the uprising hot gases as the gasification zone moved downwards. The increase in gasification time produced hotter gases which are a product of the thermo-chemical pyrolysis and gasification reactions that took place. The same phenomenon also applies to the region between T2, T3 and T4 but the magnitude of the temperatures is maintained in the order $\mathrm{T} 1>\mathrm{T} 2>\mathrm{T} 3>\mathrm{T} 4$ because of the order of movement of the combustion zone. At this maximum ER, a maximum temperature is achieved by $\mathrm{T} 3$ for all the runs. Increase in maximum temperatures for $\mathrm{T} 3$ until $700^{\circ} \mathrm{C} \pm$ 


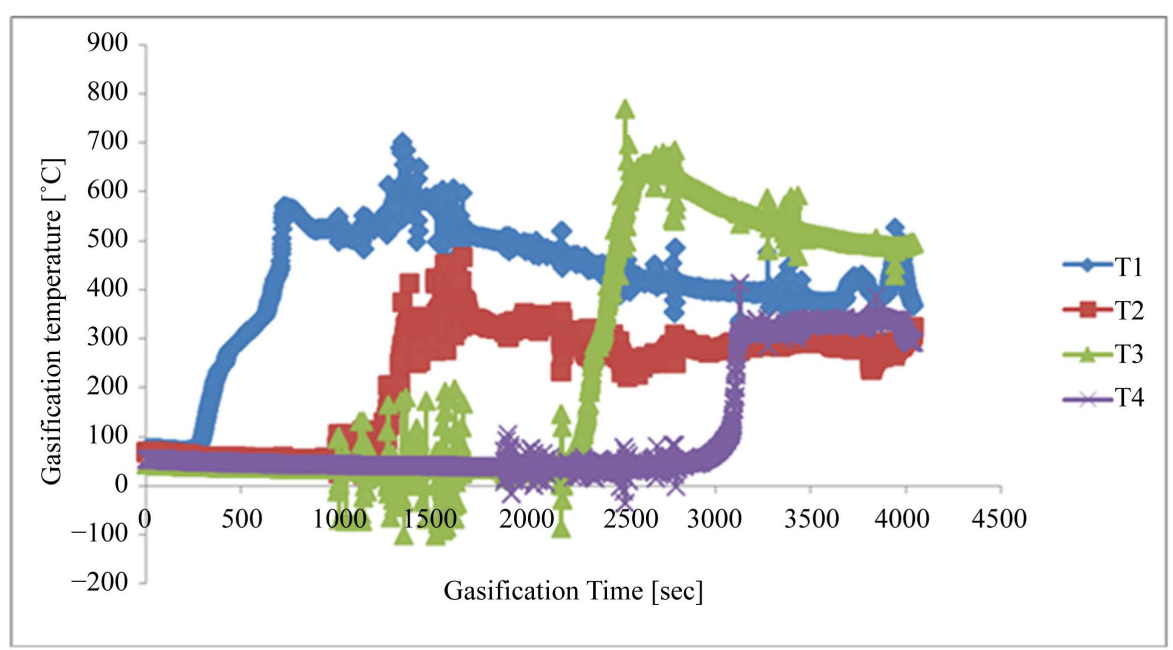

Figure 6. Variation of gasification temperature with gasification time Run 2.

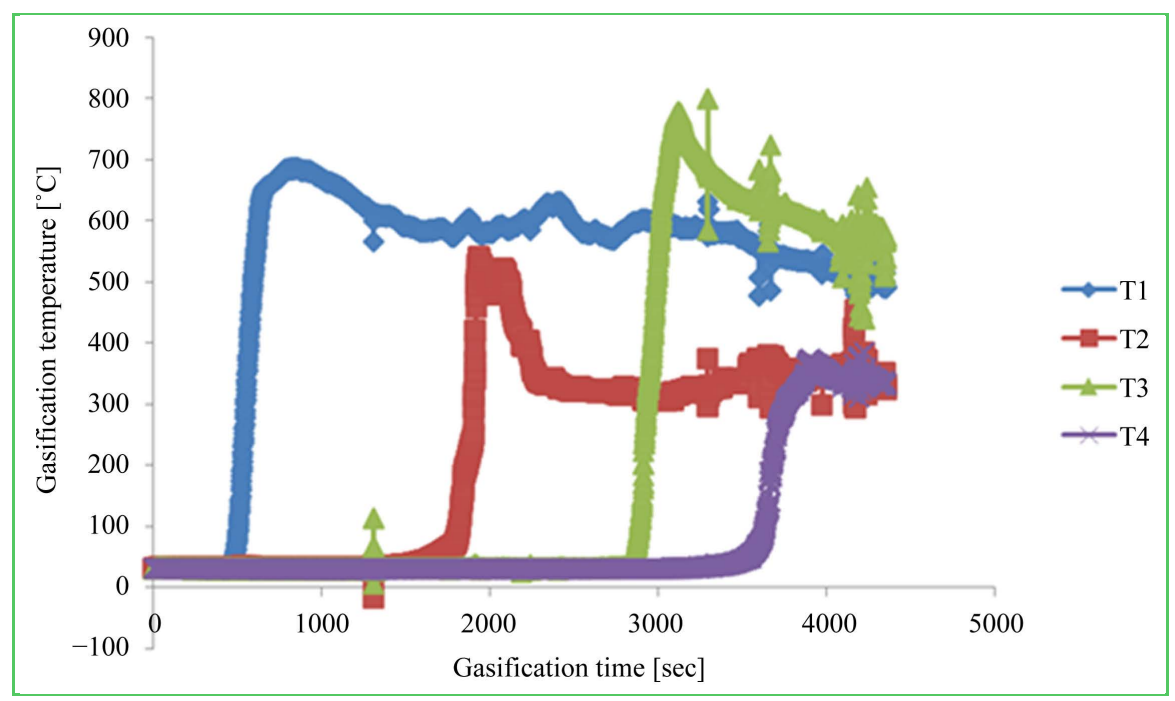

Figure 7. Variation of gasification temperature with gasification time Run 3.

$100^{\circ} \mathrm{C}$ indicate that gasification reactions occurred. The highest temperature profile build-up inside the reactor in the order high ER > medium ER > low ER confirms that maximum energy generation is experienced at high ER. Increasing ER enhances the oxidation reactions which produces more heat and increases the temperature [31].

\subsection{RHB Production from FRH at Medium ER}

The experimental results for medium ER are summarized in Table 6. The average ER was $0.364 \pm 0.031$ with an average electricity consumption and char yield of $13.2 \pm 0.9 \mathrm{Wh}$ and $22.1 \% \pm 0.4 \%$, respectively.

The average gasification time for the runs was $76.3 \pm 5.5 \mathrm{~min}$ corresponding to an average SGR of $78.9 \pm 6.0$ $\mathrm{kg} /\left(\mathrm{m}^{2} \cdot \mathrm{hr}\right)$. As before, Runs 1 and 3 were started from a cold start process while Run 2 was a direct continuation of Run 2. This explains why the gasification time and electricity consumption of Run 2 were less than that of Run 1 . The RHB was $9.5 \%$ greater than that obtained at high ER. This is because there was less air supplied to react with the FRH compared to high ER. The power consumption and SGR also decreased by $52 \%$ and $7.6 \%$ from the maximum ER, respectively.

\section{Gasification Temperature Profile for Medium ER}

By considering Figures 8-10, the average temperature achieved was largely between $400^{\circ} \mathrm{C}-700^{\circ} \mathrm{C}$ for all the 
Table 6. Summary of results for middle ER.

\begin{tabular}{|c|c|c|c|c|c|}
\hline Parameter & Run 1 & Run 2 & Run 3 & Average & $\mathrm{SD}$ \\
\hline Electricity consumption $[\mathrm{W} \cdot \mathrm{h}]$ & 13.3 & 12.2 & 14.0 & 13.2 & 0.9 \\
\hline Unburnt RH [g] & 39.4 & 29.9 & 29.6 & 33.0 & 4.60 \\
\hline Yield [\%] & 22.3 & 21.7 & 22.3 & 22.1 & 0.37 \\
\hline ER & 0.378 & 0.329 & 0.387 & 0.364 & 0.031 \\
\hline Gasification time [min] & 80 & 70 & 79 & 76.3 & 5.5 \\
\hline Ambient temperature $\left[{ }^{\circ} \mathrm{C}\right]$ & 33.15 & 33.38 & 32.67 & 33.1 & 0.4 \\
\hline $\mathrm{SGR}\left[\mathrm{kg} / \mathrm{m}^{2} \cdot \mathrm{hr}\right]$ & 74.8 & 85.9 & 76.1 & 78.9 & 6.0 \\
\hline
\end{tabular}

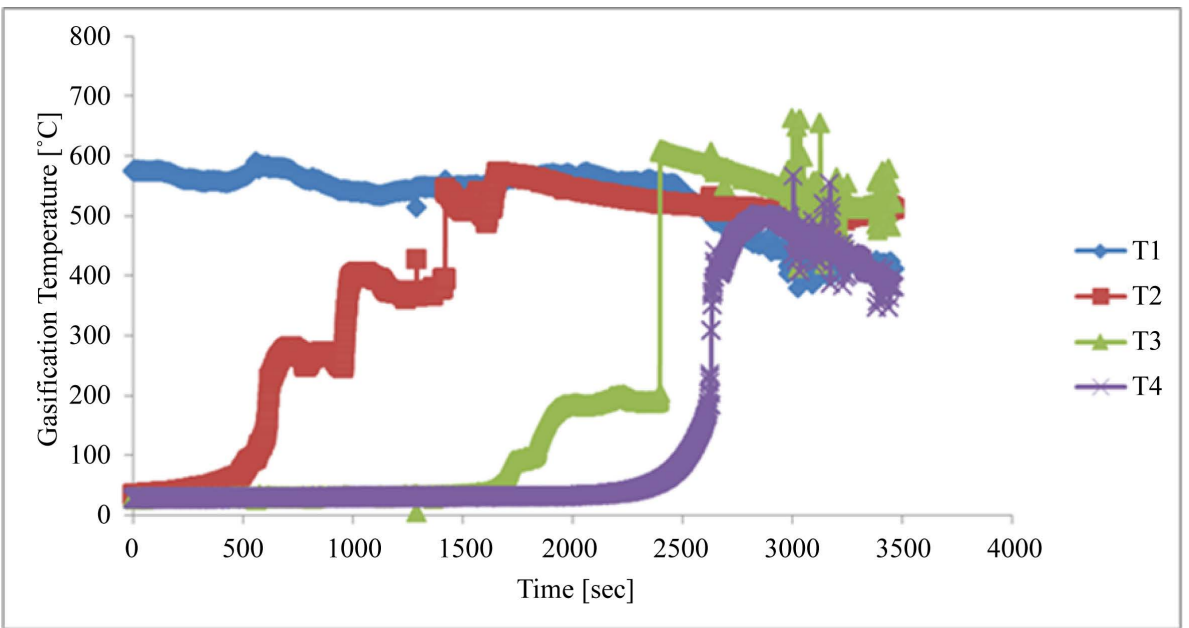

Figure 8. Variation of temperature with gasification time at medium ER Run 1.

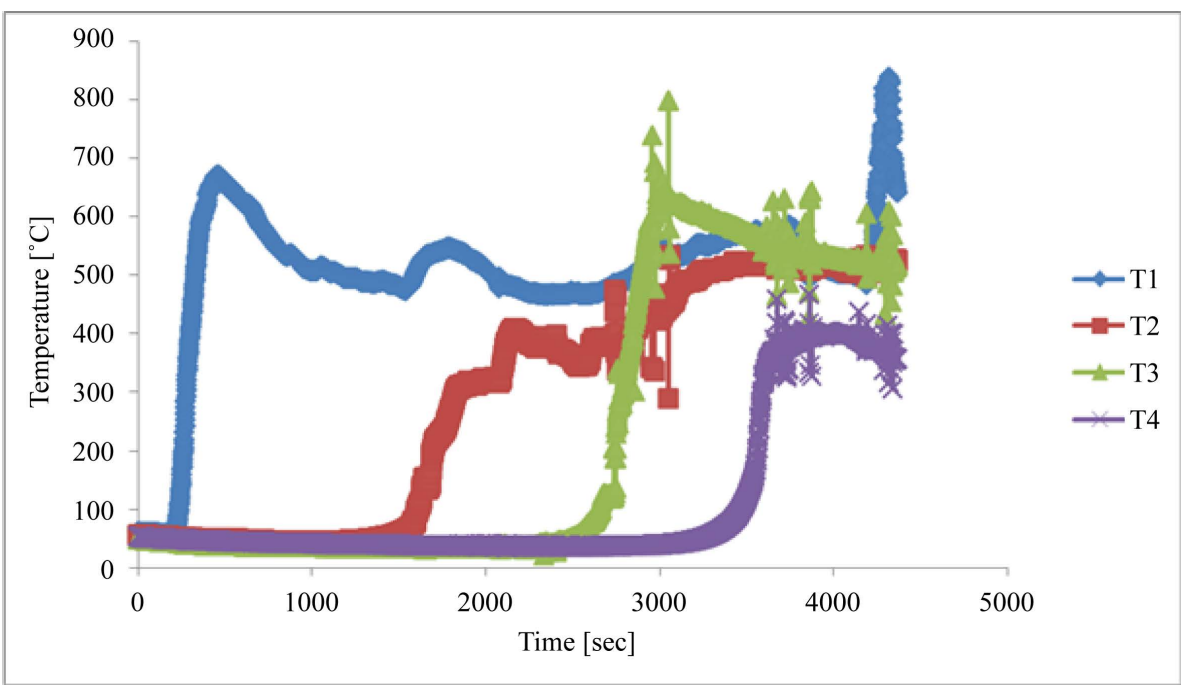

Figure 9. Variation of temperature with gasification time at middle ER Run 2.

runs. This implies that the internal energy generated at medium ER was less than that at high ER due to reduced exothermal reactions.

\subsection{RHB Production from FRH at Low ER}

The experimental results shown in Table 7 were obtained under the same initial starting velocity of $0.4 \mathrm{~m} / \mathrm{s}$ which 


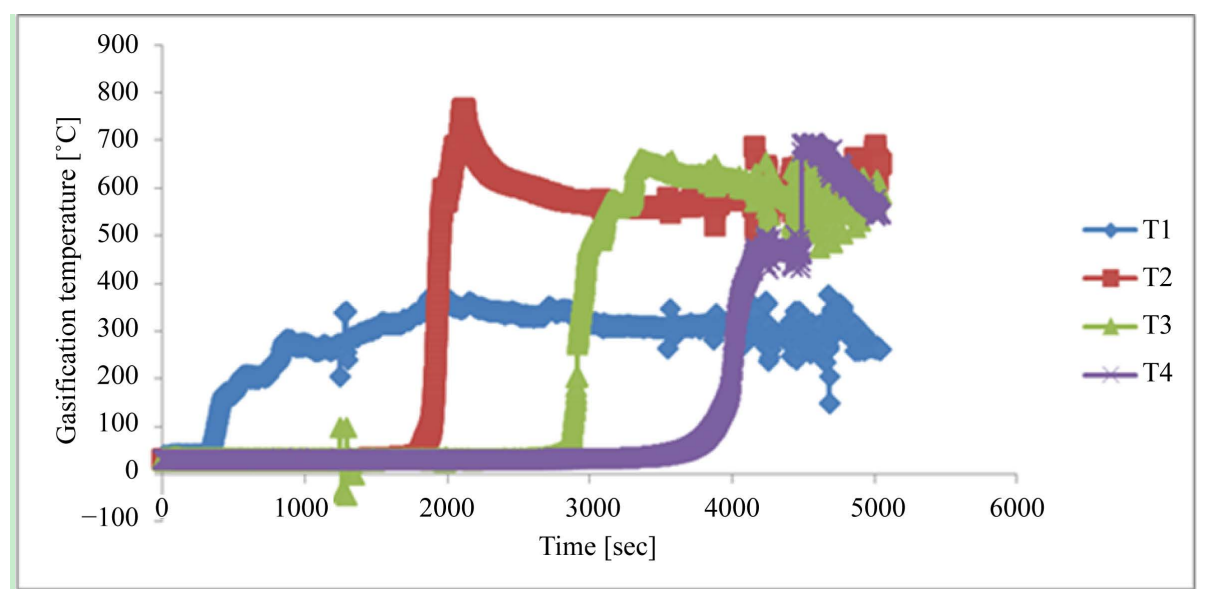

Figure 10. Variation of temperature with gasification time at middle ER Run 3.

Table 7. Summary of RH gasification experiments at low ER.

\begin{tabular}{|c|c|c|c|c|c|}
\hline Parameter & Run 1 & Run 2 & Rep 3 & Average & $\mathrm{SD}$ \\
\hline Electricity consumption $[\mathrm{W} \cdot \mathrm{h}]$ & 14.8 & 14.0 & 14.5 & 14.4 & 0.4 \\
\hline Unburnt FRH [g] & 30.4 & 25.3 & 21.6 & 25.8 & 3.6 \\
\hline Yield [\%] & 26.31 & 25.27 & 26.07 & 25.9 & 0.5 \\
\hline ER & 0.2911 & 0.297 & 0.2867 & 0.2916 & 0.005 \\
\hline Gasification Time [min] & 120 & 111 & 120 & 117 & 5 \\
\hline Ambient Temperature $\left[{ }^{\circ} \mathrm{C}\right]$ & 28.25 & 30.39 & 28.48 & 29.04 & 1.2 \\
\hline $\mathrm{SGR}\left[\mathrm{kg} / \mathrm{m}^{2} \cdot \mathrm{hr}\right]$ & 50.1 & 54.3 & 50.3 & 51.6 & 2.4 \\
\hline
\end{tabular}

increased with gasification time due to the decrease in the total specific resistance of RH. The average ER for low ER was $0.2916 \pm 0.005$, with an average electricity consumption and char yield of $14.4 \pm 0.4 \mathrm{Wh}$ and $25.9 \%$ $\pm 0.5 \%$, respectively. The average gasification time was $117 \pm 5 \mathrm{~min}$ which corresponds to an average SGR of $51.6 \pm 2.4 \mathrm{~kg} /\left(\mathrm{m}^{2} \cdot \mathrm{hr}\right)$. At this ER setting, there was a higher yield of RHB compared to medium and high ER with a char yield increase by $22.8 \%$ and a decrease in electricity consumption of $47.8 \%$ between the high and low ER. In addition, the SGR decreased by 39.6\%. To obtain high RHB yield at low electricity consumption in the OBRHG, the low ER is recommended.

\section{Gasification Temperature Profile for Low ER}

From Figure 11 and Figure 12, the general observation is that the temperatures at low ER did not consistently rise as high as the medium and high ER. The major temperatures dominated in the range between $200^{\circ} \mathrm{C}-350^{\circ} \mathrm{C}$. This suggests that pyrolysis reactions dominate inside the reactor and the composition of syngas within the low ER contains less $\mathrm{CO}$ and $\mathrm{H}_{2}$ which are a function of temperature.

\subsection{Effect of RH Particle Size on Yield at Different ER}

The char yield from fine and original RH decreased as the ER increased (Figure 13 and Table 8). The decrease is because an increase in ER provides more air which reacts with RH to convert it into heat and gases. Generation of more heat increases the rate of decomposition of RH. Low ER generates low temperature. The high yield of biochar at low temperatures indicates that the material was only partially gasified [32]. The statistical analysis revealed that the yields at different ERs were highly significantly different $(p=1.18 \mathrm{E}-06)$.

The trend of results for ER versus yield, ER versus SGR and ER versus gasification time are all in agreement with those for FRH gasification as discussed above (Section 3.2 - 3.6). However, to achieve a similar yield of $30 \%$, it takes a shorter time $(69 \mathrm{~min})$ compared to $117 \pm 5 \mathrm{~min}$ with FRH gasification. This subsequently accounts for the difference in SGR. 


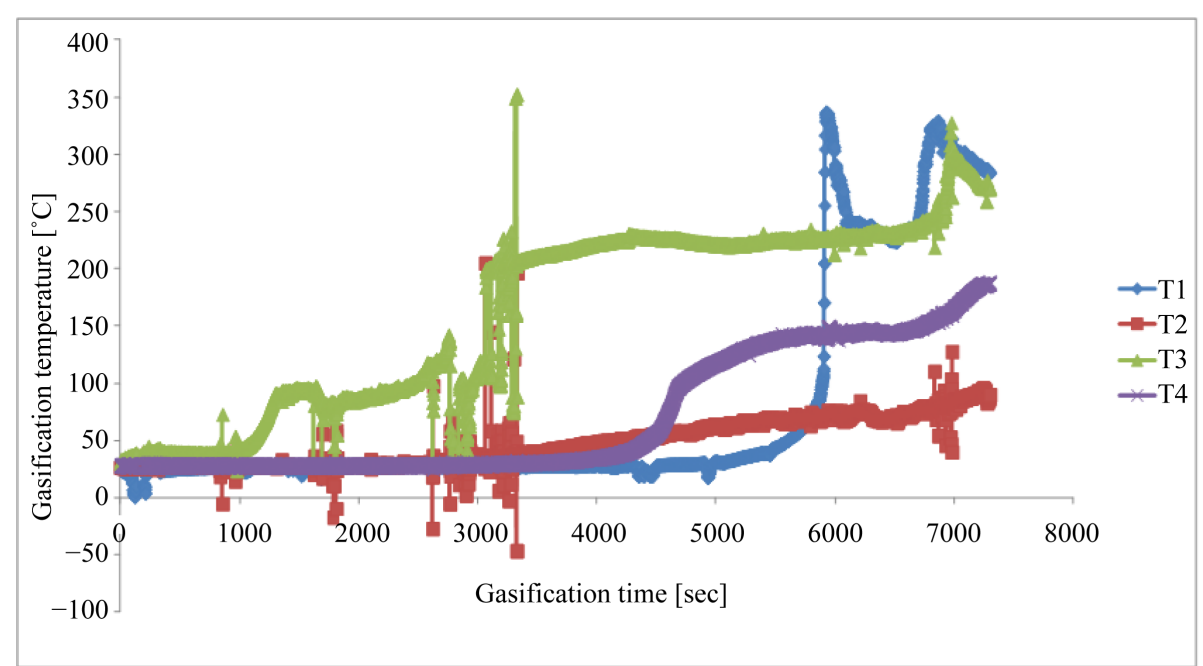

Figure 11. Variation of incoming air velocity with gasification time at lower ER (Run 1).

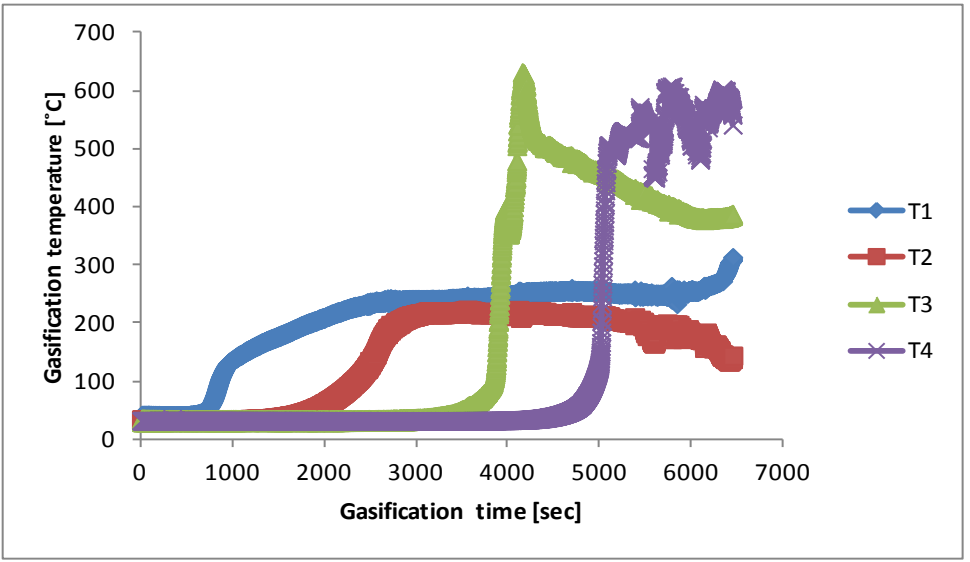

Figure 12. Variation of gasification temperature with time at low ER (Run 2).

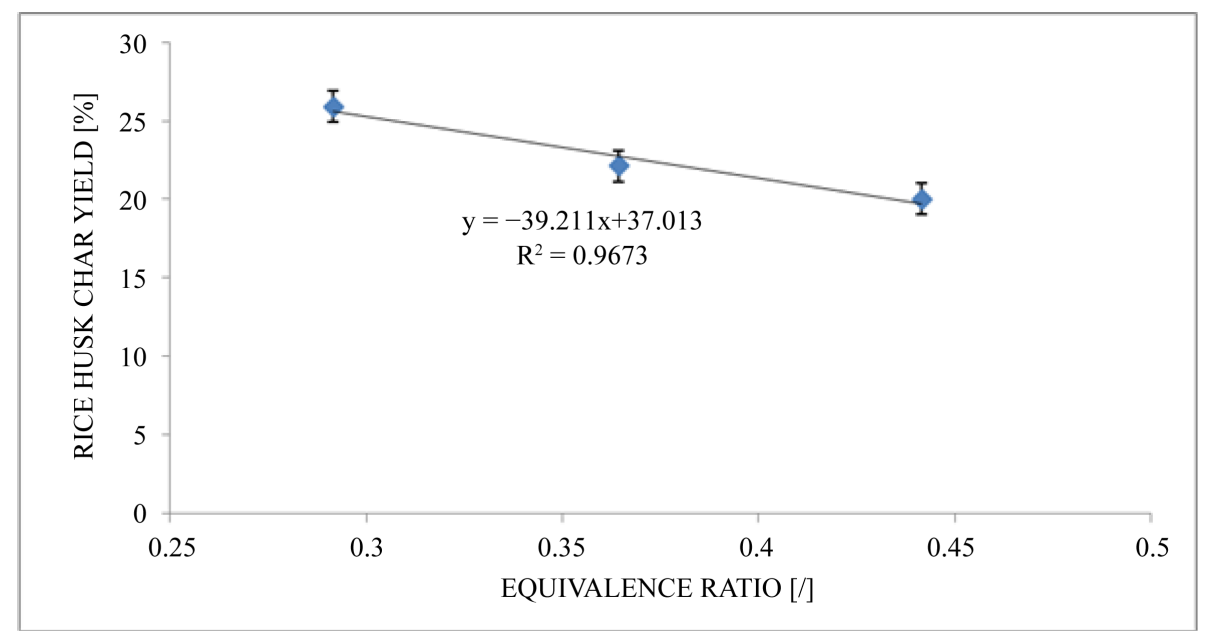

Figure 13. Variation of RHB yield from FRH as a function of ER.

Variation in temperature profile along the reactor height is revealed in Figures 14-16. The maximum temperatures for T1, T2, T3 and T4 increased as the ER increased. For example, the maximum temperature (T4) meas- 
Table 8. Results for major parameters during ORH gasification.

\begin{tabular}{cccc}
\hline Parameter & High ER & Medium ER & Low ER \\
\hline Yield [\%] & $16.6 \pm 0.62$ & $25.9 \pm 0.7$ & $30.5 \pm 0.9$ \\
ER & $0.530 \pm 0.007$ & $0.219 \pm 0.016$ & $0.112 \pm 0.020$ \\
Gasification time [min] & $25.7 \pm 1.2$ & $44 \pm 1.73$ & $69 \pm 0$ \\
SGR $\left[\mathrm{kg} / \mathrm{m}^{2} \cdot \mathrm{hr}\right]$ & $127 \pm 1$ & $74.4 \pm 1.7$ & 47.5 \\
\hline
\end{tabular}

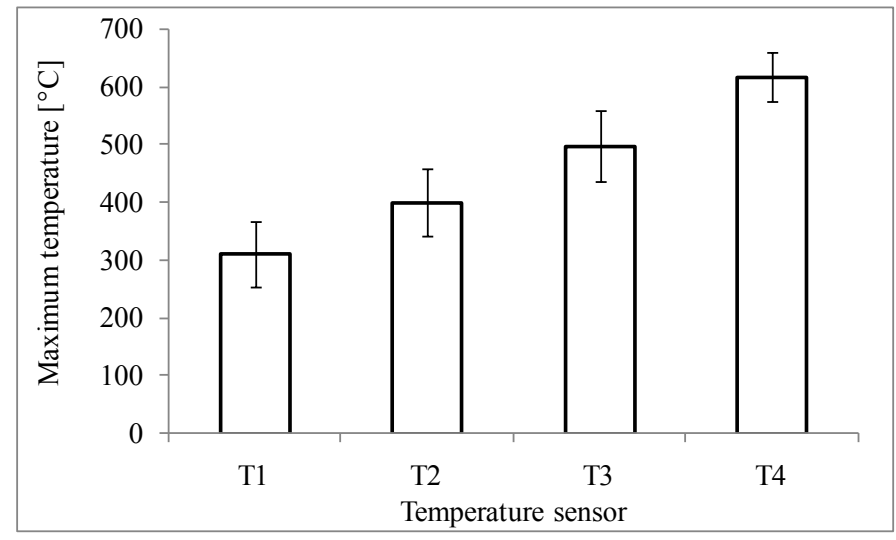

Figure 14. Maximum pyrolysis temperatures recorded at different sensor locations during ORH pyrolysis at low ER $(n=3)$.

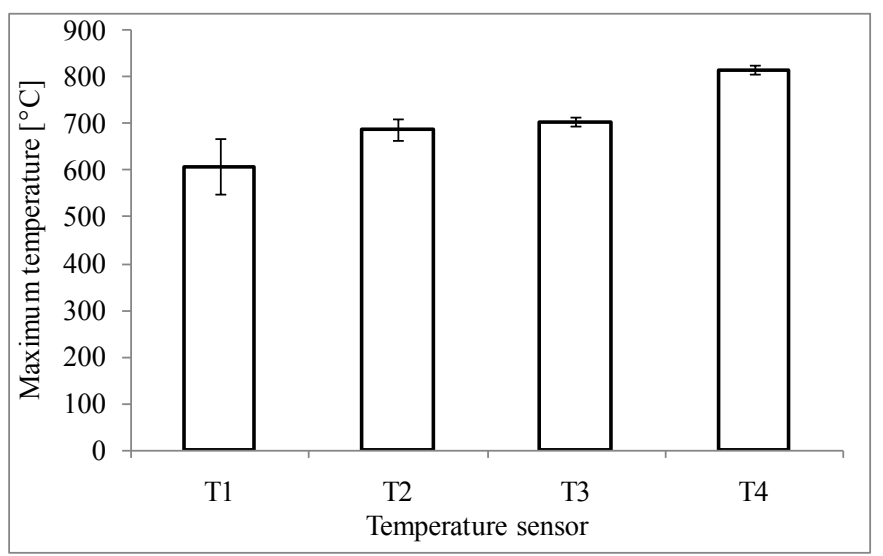

Figure 15. Maximum gasification temperatures recorded at different sensor locations during ORH gasification at medium ER $(n=3)$.

ured was about $610^{\circ} \mathrm{C}$ for low ER, $810^{\circ} \mathrm{C}$ for medium ER and about $920^{\circ} \mathrm{C}$ for high ER, and their corresponding gasification time of $60 \mathrm{~min}$ for low ER, $40 \mathrm{~min}$ for medium ER and $25 \mathrm{~min}$ for high ER. Increasing ER decreased gasification time because the rate of chemical reactions becomes faster with supply of more oxygen. The recorded temperature profiles demonstrate that the combustion zone moved from top to bottom as would be expected for a top lit gasifier.

\subsection{Effect of ER on $\mathrm{pH}$}

The variation of $\mathrm{pH}$ with ER is shown in Figure 17. The observed $\mathrm{pH}$ ranged between $9.36 \pm 0.11$ to $9.64 \pm 0.03$ was similar to values reported for biochar produced from safflower seed press cake, sugar beet tailings, sewage sludge and sugarcane bagasse at high temperature [33]-[35]. From the statistical analysis, there is significant difference between $\mathrm{pH}$ as ER changes from low (L) to medium (M) and from medium (M) to high (H). The alkaline nature of RHB may be due to a combination of surface chemistry and high AC with significant amounts of 


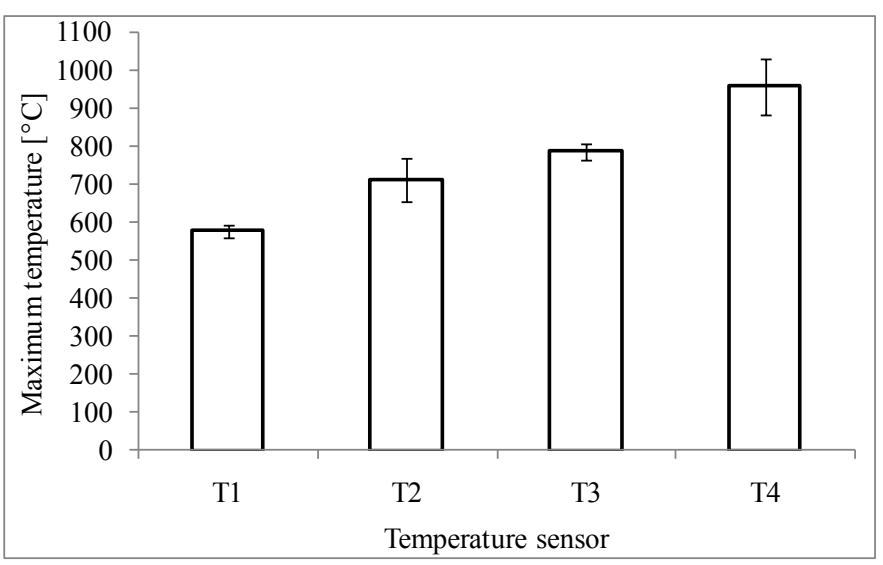

Figure 16. Maximum gasification temperatures recorded at different sensor locations during ORH gasification at high ER $(n=3)$.

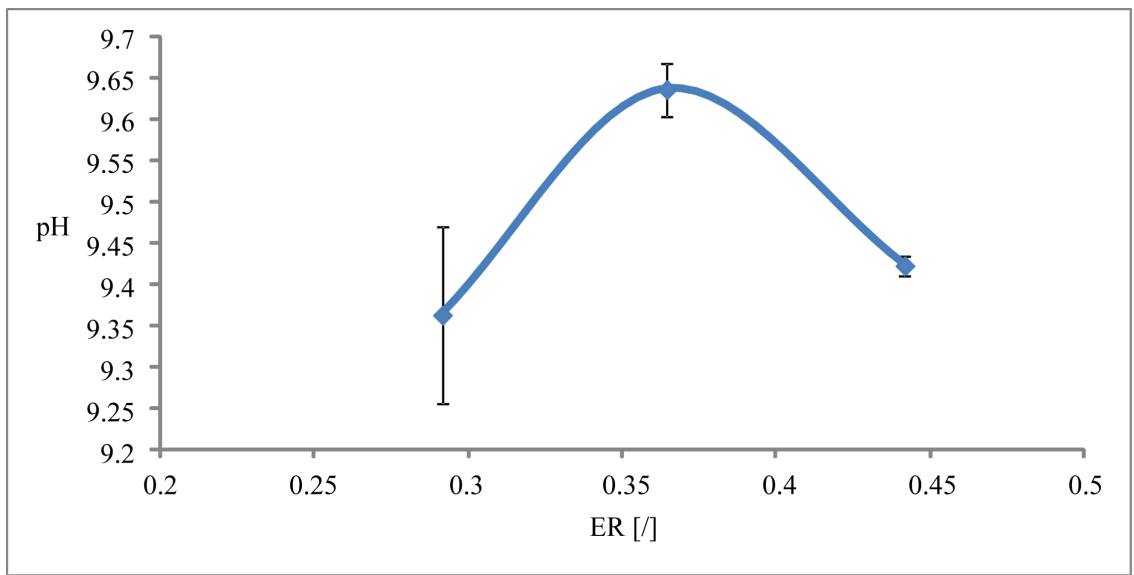

Figure 17. Variation of $\mathrm{pH}$ with ER.

silica, carbonates of alkali and alkali earth metals. The $\mathrm{pH}$ increases as the ER increase and gradually decreases. The slight decrease may be due to the relative change in the concentration of inorganic carbonates and watersoluble anions present in RHB at high ER. At low ER, there is a possibility of pyrotic acids formed during tar formation with biochar exhibiting the alkaline property. The biochar $\mathrm{pH}$ is influenced by production temperature and duration [36].

\section{Conclusion}

The effect of ER on RHB properties, electricity consumption, biochar yield and SGR, as well as reactor temperature, was investigated. One way ANOVA demonstrated a statistically significant difference in yield, $\mathrm{pH}, \mathrm{VM}$ and $\mathrm{AC}$ as ER varied from low to high. In order to obtain a high RHB yield at low electricity cost and $\mathrm{H} / \mathrm{C}$ ratio (as required by IBI), a low ER is recommended. $\mathrm{O} / \mathrm{C}$ and $\mathrm{H} / \mathrm{C}$ ratio trend appears to be different between allothermal and autothermal gasifiers. Air pollution control for smoke emissions at low ER needs further investigation.

\section{Acknowledgements}

Financial support was provided by the Norwegian Research Council's "Norway-Global partner" programme, Project 203901/H30 "Biochar on acidic agricultural lands in South-East Asia: Sequestering carbon and improving crop yield". 


\section{References}

[1] Verheijen, F., Jeffery, S., Bastos, A.C. and van der Velde, M. (2009) Biochar Application to Soils-A Critical Scientific Review of Effects on Soil Properties, Processes and Functions. Office for the Official Publications of the European Communities, Luxemburg, 149.

[2] Lehmann, J. (2007) Bio-Energy in the Black. Frontiers in Ecology and the Environment, 5, 381-387. http://dx.doi.org/10.1890/1540-9295(2007)5[381:BITB]2.0.CO;2

[3] Duku, M.H., Gu, S. and Hagan, E.B. (2011) Biochar Production Potential in Ghana-A Review. Renewable and Sustainable Energy Reviews, 15, 3539-3551. http://dx.doi.org/10.1016/j.rser.2011.05.010

[4] Amonette, J. and Joseph, S. (2009) Characteristics of Biochar: Micro-Chemical Properties. In: Lehmann, J. and Joseph, S., Eds., Biochar for Environmental Management: Science and Technology, Earthscan, London, 33-52.

[5] Tye, Y.Y., Lee, K.T., Wan Abdullah, W.N. and Leh, C.P. (2011) Second-Generation Bioethanol as a Sustainable Energy Source in Malaysia Transportation Sector: Status, Potential and Future Prospects. Renewable and Sustainable Energy Reviews, 15, 4521-4536. http://dx.doi.org/10.1016/j.rser.2011.07.099

[6] Mekhilef, S., Saidur, R., Safari, A. and Mustaffa, W.E.S.B. (2011) Biomass Energy in Malaysia: Current State and Prospects. Renewable and Sustainable Energy Reviews, 15, 3360-3370. http://dx.doi.org/10.1016/j.rser.2011.04.016

[7] Shafie, S.M., Mahlia, T.M.I., Masjuki, H.H. and Ahmad-Yazid, A. (2012) A Review on Electricity Generation Based on Biomass Residue in Malaysia. Renewable and Sustainable Energy Reviews, 16, 5879-5889. http://dx.doi.org/10.1016/j.rser.2012.06.031

[8] Ng, W.P.Q., Lam, H.L., Ng, F.Y., Kamal, M. and Lim, J.H.E. (2012) Waste-to-Wealth: Green Potential from Palm Biomass in Malaysia. Journal of Cleaner Production, 34, 57-65. http://dx.doi.org/10.1016/j.jclepro.2012.04.004

[9] Cheng, G., Li, Q., Qi, F., Xiao, B., Liu, S. and Hu, Z.P.H. (2012) Allothermal Gasification of Biomass Using Micron Size Biomass as External Heat Source. Bioresource Technology, 107, 471-475. http://dx.doi.org/10.1016/j.biortech.2011.12.074

[10] Apaydın-Varol, E. and Pütün, A.E. (2012) Preparation and Characterization of Pyrolytic Chars from Different Biomass Samples. Journal of Analytical and Applied Pyrolysis, 98, 29-36. http://dx.doi.org/10.1016/j.jaap.2012.07.001

[11] ASTM D1762-84 (2013) Standard Test Method for Chemical Analysis of Wood Charcoal. ASTM International, West Conshohocken. http://www.astm.org/Standards/D1762.htm

[12] FAO (1983) Simple Technologies for Charcoal Making. FAO Forestry Paper 41, Rome, ISBN 92-5-101328-1. http://www.fao.org/docrep/x5328e/x5328e00.HTM

[13] Zainal, Z.A., Rifau, A., Quadir, G.A. and Seetharamu, K.N. (2002) Experimental Investigation of a Downdraft Biomass Gasifier. Biomass and Bioenergy, 23, 283-289. http://dx.doi.org/10.1016/S0961-9534(02)00059-4

[14] Belonio, A.T. (2005) Rice Husk Gas Stove Handbook. Appropriate Technology Center, Department of Agricultural Engineering and Environmental Management College of Agriculture, Central Philippine University, Iloilo City.

[15] Maiti, S., Dey, S., Purakayastha, S. and Ghosh, B. (2006) Physical and Thermochemical Characterization of Rice Husk Char as a Potential Biomass Energy Source. Bioresource Technology, 97, 2065-2070. http://dx.doi.org/10.1016/j.biortech.2005.10.005

[16] Tiangco, V.M., Jenkins, B.M. and Goss, J.R. (1996) Optimum Specific Gasification Rate for Static Bed Rice Hull Gasifiers. Biomass and Bioenergy, 11, 51-62. http://dx.doi.org/10.1016/0961-9534(95)00110-7

[17] Permchart, W. and Kouprianov, V.I. (2004) Emission Performance and Combustion Efficiency of a Conical Fluidized-Bed Combustor Firing Various Biomass Fuels. Bioresource Technology, 92, 83-91. http://dx.doi.org/10.1016/j.biortech.2003.07.005

[18] Wannapeera, J., Worasuwannarak, N. and Pipatmanomai, S. (2008) Product Yields and Characteristics of Rice Husk, Rice Straw and Corncob during Fast Pyrolysis in a Drop-Tube/Fixed-Bed Reactor. Songklanakarin Journal of Science \& Technology, 30, 393-404.

[19] Guerrero, M., Ruiz, M.P., Millera, Á., Alzueta, M.U. and Bilbao, R. (2008) Characterization of Biomass Chars Formed under Different Devolatilization Conditions: Differences between Rice Husk and Eucalyptus. Energy \& Fuels, 22, 1275-1284. http://dx.doi.org/10.1021/ef7005589

[20] Raveendran, K., Ganesh, A. and Khilar, K.C. (1995) Influence of Mineral Matter on Biomass Pyrolysis Characteristics. Fuel, 74, 1812-1822. http://dx.doi.org/10.1016/0016-2361(95)80013-8

[21] Fu, P., Yi, W., Bai, X., Li, Z., Hu, S. and Xiang, J. (2011) Effect of Temperature on Gas Composition and Char Structural Features of Pyrolyzed Agricultural Residues. Bioresource Technology, 102, 8211-8219. http://dx.doi.org/10.1016/j.biortech.2011.05.083

[22] Peterson, S.C. and Jackson, M. (2014) Simplifying Pyrolysis: Using Gasification to Produce Corn Stover and Wheat 
Straw Biochar for Sorptive and Horticultural Media. Industrial Crops and Products, 53, 228-235. http://dx.doi.org/10.1016/j.indcrop.2013.12.028

[23] Downie, A., Munroe, P., Cowie, A., Van Zwieten, L. and Lau, D.M.S. (2012) Biochar as a Geoengineering Climate Solution: Hazard Identification and Risk Management. Critical Reviews in Environmental Science and Technology, 42, 225-250. http://dx.doi.org/10.1080/10643389.2010.507980

[24] Lua, A.C., Yang, T. and Guo, J. (2004) Effects of Pyrolysis Conditions on the Properties of Activated Carbons Prepared from Pistachio-Nut Shells. Journal of Analytical and Applied Pyrolysis, 72, 279-287. http://dx.doi.org/10.1016/j.jaap.2004.08.001

[25] Mukome, F.N.D., Zhang, X., Silva, L.C.R., Six, J. and Parikh, S.J. (2013) Use of Chemical and Physical Characteristics to Investigate Trends in Biochar Feedstocks. Journal of Agricultural and Food Chemistry, 61, 2196-2204. http://dx.doi.org/10.1021/jf3049142

[26] Wiedner, K., Rumpel, C., Steiner, C., Pozzi, A., Maas, R. and Glaser, B. (2013) Chemical Evaluation of Chars Produced by Thermochemical Conversion (Gasification, Pyrolysis and Hydrothermal Carbonization) of Agro-Industrial Biomass on a Commercial Scale. Biomass and Bioenergy, 59, 264-278. http://dx.doi.org/10.1016/j.biombioe.2013.08.026

[27] Manyà, J.J., Ortigosa, M.A., Laguarta, S. and Manso, J.A. (2014) Experimental Study on the Effect of Pyrolysis Pressure, Peak Temperature, and Particle Size on the Potential Stability of Vine Shoots-Derived Biochar. Fuel, 133, 163172. http://dx.doi.org/10.1016/j.fuel.2014.05.019

[28] http://www.biochar-international.org/sites/default/files/IBI_Biochar_Standards_V2.0_final.pdf

[29] Ryu, C., Yang, Y.B., Khor, A., Yates, N.E., Sharifi, V.N. and Swithenbank, J. (2006) Effect of Fuel Properties on Biomass Combustion: Part I. Experiments-Fuel Type, Equivalence Ratio and Particle Size. Fuel, 85, 1039-1046. http://dx.doi.org/10.1016/j.fuel.2005.09.019

[30] Zhang, Y.N., Li, B.X., Li, H.T. and Liu, H. (2011) Thermodynamic Evaluation of Biomass Gasification with Air in Autothermal Gasifiers. Thermochimica Acta, 519, 65-71. http://dx.doi.org/10.1016/j.tca.2011.03.005

[31] Najdat, S. (2014) Gasification of Pine Wood Chips with Air-Steam in Fluidized Bed. Doctoral Thesis, Brno University of Technology. https://www.vutbr.cz/www_base/zav_prace_soubor_verejne.php?file_id=93748

[32] Katyal, S., Thambimuthu, K. and Valix, M. (2006) Carbonisation of Bagasse in a Fixed Bed Reactor: Influence of Process Variables on Char Yield and Characteristics. Renewable Energy, 28, 713-725.

[33] Angin, D. (2013) Effect of Pyrolysis Temperature and Heating Rate on Biochar Obtained from Pyrolysis of Safflower Seed Press Cake. Bioresource Technology, 128, 593-597. http://dx.doi.org/10.1016/j.biortech.2012.10.150

[34] Yao, Y., Gao, B., Inyang, M., Zimmerman, A.R., Cao, X., Pullammanappallil, P. and Yang, L. (2011) Biochar Derived from Anaerobically Digested Sugar Beet Tailings: Characterization and Phosphate Removal Potential. Bioresource Technology, 102, 6273-6278. http://dx.doi.org/10.1016/j.biortech.2011.03.006

[35] Jindarom, C., Meeyoo, V., Kitiyanan, B., Rirksomboon, T. and Rangsunvigit, P. (2007) Surface Characterization and Dye Adsorptive Capacities of Char Obtained from Pyrolysis/Gasification of Sewage Sludge. Chemical Engineering Journal, 133, 239-246. http://dx.doi.org/10.1016/j.cej.2007.02.002

[36] Zhang, X.C. and Liu, X.H. (2012) Effect of Biochar on pH of Alkaline Soils in the Loess Plateau: Results from Incubation Experiments. International Journal of Agriculture \& Biology, 14, 745-750. 
Scientific Research Publishing (SCIRP) is one of the largest Open Access journal publishers. It is currently publishing more than 200 open access, online, peer-reviewed journals covering a wide range of academic disciplines. SCIRP serves the worldwide academic communities and contributes to the progress and application of science with its publication.

Other selected journals from SCIRP are listed as below. Submit your manuscript to us via either submit@scirp.org or Online Submission Portal.
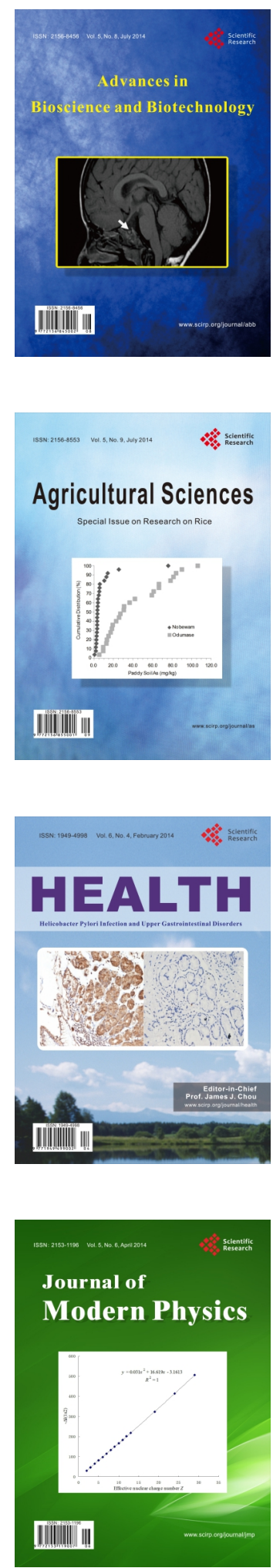
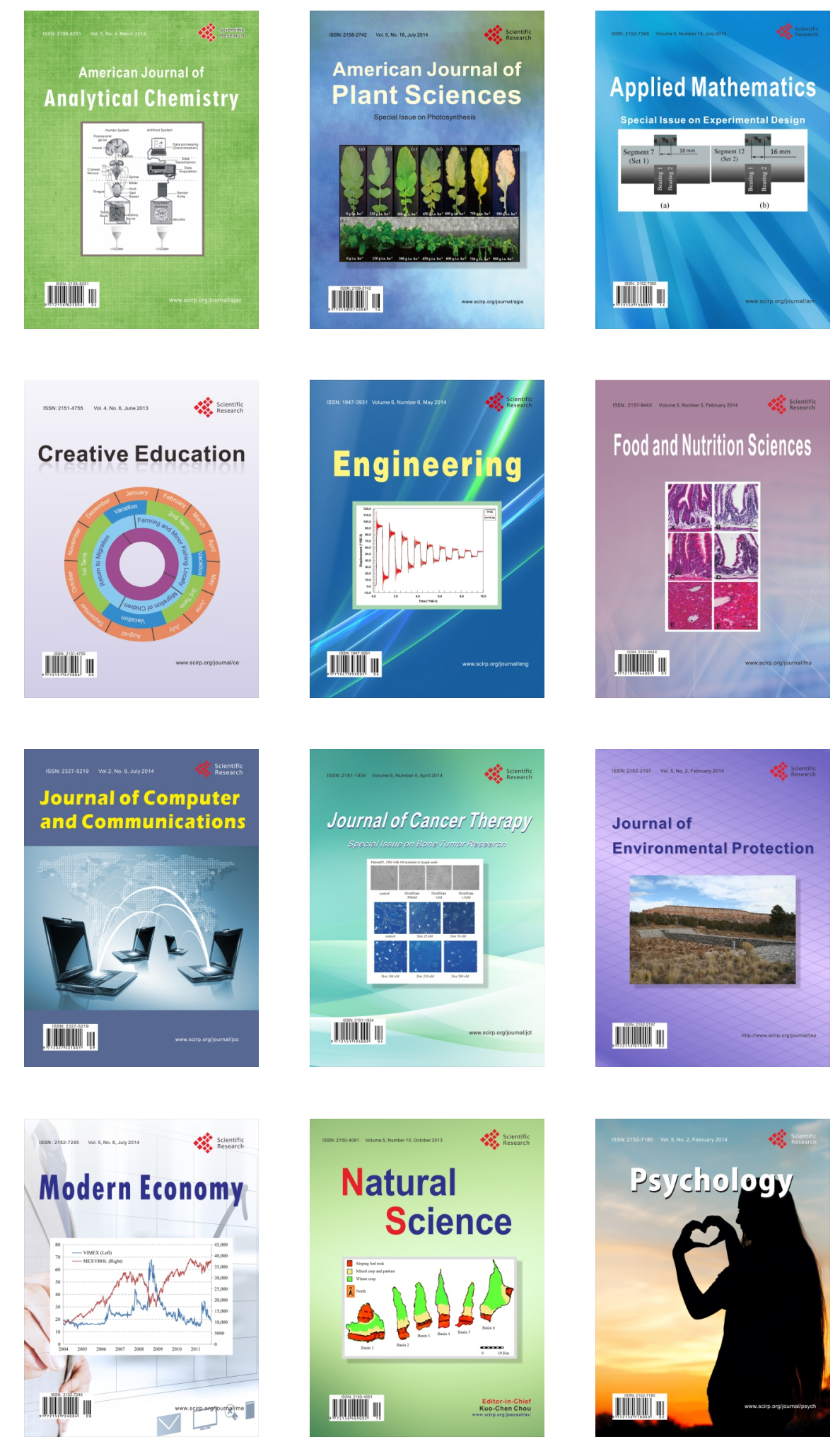